\title{
Psicologia e Neurociência cognitivas: Alguns avanços recentes e implicações para a educação
}

\author{
Paulo Estevão Andrade \\ Colégio Criativo \\ Paulo Sérgio T. do Prado \\ Universidade Estadual Paulista
}

\begin{abstract}
Resumo
Partindo da contribuição de autores como Piaget e Vygotsky para a compreensão do desenvolvimento psicológico, o texto comenta alguns importantes avanços recentes na pesquisa em psicologia infantil e confronta seus resultados com posturas anteriores. Um ponto de destaque relaciona-se com o desenvolvimento de certas habilidades perceptivas e cognitivas as quais, de acordo com algumas evidências, têm sua gênese em idades inferiores às que se acreditava há algum tempo. Adicionalmente, comentam-se importantes achados das neurociências, e mais particularmente da neuropsicologia cognitiva, identificando áreas cerebrais responsáveis por determinadas tarefas cognitivas e também algumas de suas associações. A conclusão aponta para a necessidade de os profissionais da educação e os currículos escolares levarem em consideração esses avanços científicos para que se produzam melhorias na eficácia do processo pedagógico.
\end{abstract}

Palavras-chave: Psicologia cognitiva; neurociências; educação.

\begin{abstract}
Cognitive psychology and neuroscience: recent advances and implications for education

Starting with the contribution from psychologists like Piaget and Vygotsky to understanding psychological development the authors comment on some important recent advances in infant psychology research and confront its results with previous postures. In particular, certain perceptual and cognitive skills' development are stressed, since there are evidences that their genesis is earlier than previously believed. Additionally, important findings of neuroscience and cognitive neuropsychology are commented upon, as well as brain areas responsible for certain specific cognitive tasks, and some of its associations are identified. The conclusion points out to the need that education professionals and the curriculum take these scientific advances into account in order to ameliorate the effectiveness of the pedagogical process.
\end{abstract}

Keywords: Cognitive Psychology; brain sciences; education.

Dois autores mundialmente muito influentes na psicologia do desenvolvimento são o suíço Jean Piaget (1896-1980) e o bielorusso Lev Semenovitch Vygotsky (1896-1934). As idéias de ambos têm importantes implicações educacionais e exercem uma influência marcante na educação brasileira. Menos conhecidas entre nossos educadores, no entanto são as pesquisas que, há mais de duas décadas, vêm sendo desenvolvidas por diversos autores no campo da psicologia e no da neurociência cognitiva, as quais têm enriquecido sobremaneira o debate sobre a cognição humana. Confrontar alguns resultados e conclusões dessas pesquisas com as proposições de Piaget e Vygotsky e iniciar uma discussão sobre algumas possíveis implicações educacionais são os objetivos do artigo. Considerando a popularidade daqueles dois autores, apresentaremos de modo condensado algumas de suas colocações, detendo-nos um pouco mais na apresentação de pesquisas mais recentes. Contudo, chamamos a atenção para o fato de que não será uma apresentação exaustiva, pois dado o grande volume dessas pesquisas teremos, necessariamente, de ser seletivos.

\section{Contribuições de Piaget e de Vygotsky}

Piaget via o desenvolvimento intelectual ou cognitivo como a aquisição de conhecimento pela criança. Ele não admitia que o conhecimento se reduzisse a impressões do meio sobre a folha em branco da mente (empirismo), nem que as estruturas cognitivas desabrocham automaticamente a seu tempo por determinação genética (inatismo). Segundo ele, o conhecimento é construído pela criança nas suas interações com o meio; por isso se dizia construtivista.

Nas suas interações com o meio a criança vai se adaptando a ele. A adaptação consiste de dois processos complementares: assimilação e acomodação. Considerando que, de acordo com o autor, conhecer é interpretar, atribuir significados, a criança faz isso assimilando elementos do meio aos seus esquemas e estruturas cognitivas e acomodandoos às novas exigências que o meio vai lhe impondo.

Piaget interpretou suas observações como um reflexo de diferenças qualitativas na capacidade de representações mentais e do raciocínio das crianças, a qual evoluiria ao longo de estágios sucessivos de desenvolvimento através dos quais a criança passa de estados de menos conhecimento para estados de mais conhecimento. Os estágios são universais, isto é, comuns a todo ser humano. Eles se sucedem numa 
seqüência fixa e ocorrem em determinadas faixas de idade. Finalmente, os estágios são de complexidade crescente e são em número de quatro, resumidos a seguir.

No estágio sensório-motor (do nascimento a um ano e meio, aproximadamente), a criança vê os objetos, agarra-os, balança-os para vê-los movendo-se ou ouvir sons que eventualmente produzam, leva-os à boca para sugar etc. É assim que ela interage com os elementos de seu ambiente: através de seus esquemas sensorial e motor, e atribui-lhes significado - "isso é para sugar, aquilo é para chacoalhar" e assim por diante. A ausência da linguagem impossibilita à criança representar mentalmente a realidade. Um objeto que tenha sido removido de seu campo visual é como se simplesmente tivesse deixado de existir, por isso ela não o procurará.

No início do estágio pré-operacional (de dois a seis anos, mais ou menos), a criança já se locomove por si mesma e em pouco tempo seu vocabulário amplia-se vertiginosamente. Isso altera significativamente suas interações com o meio físico e também com o social. Ela fará perguntas e criará "teorias" sobre fatos que presencia: "por que a lua segue a gente?". Atribuirá qualidades materiais a coisas imateriais: "o sonho entrou no meu quarto"; e subjetividade a coisas inanimadas: "a bola não quer parar". Embora a criança já tenha o conceito de objeto permanente, ela ainda não desenvolveu a noção de conservação. Seu pensamento ainda não é dotado de reversibilidade. $\mathrm{Na}$ prova de conservação de número, por exemplo, ela não coordena simultaneamente as dimensões comprimento e densidade das fileiras (de fichas ou quaisquer outros elementos). Dirá que tem mais itens a fileira mais longa, mesmo que inicialmente seus elementos se apresentassem em correspondência uma-um com os de outra fileira. Isto é, a criança desse estágio não concebe um retorno da fileira alongada ao seu estado inicial. E ignora que o aumento do comprimento é compensado pela diminuição da densidade (veja Piaget \& Szeminska, 1981).

$\mathrm{O}$ pensamento torna-se progressivamente mais reversível, no estágio operacional concreto (de seis ou sete a 12 anos), mas a criança só é capaz de representar e operar mentalmente situações que vivencia concretamente. Continuando com o exemplo da prova de conservação de número, ela conceberá a possibilidade de retorno da fileira mais longa ao seu estado inicial. Também coordenará as dimensões comprimento e densidade, sabendo que o aumento em uma delas é compensado pela diminuição na outra e afirmará que ambas as fileiras têm o mesmo número de itens. Ademais, terá consciência de que o acréscimo de um item a uma coleção a tornará maior, assim como a subtração de um item a tornará menor.

O estágio operacional formal, que se inicia aos 11/12 anos, caracteriza-se pelo pleno desenvolvimento do raciocínio lógico-matemático, capacitando a criança a representar e operar mentalmente sobre a realidade num nível inteiramente abstrato.

Vygotsky ambicionava edificar uma ciência psicológica mais totalizadora do que as teorias existentes à sua época. O fundamento dessa ciência se constituiria de três elementos: o entendimento de que o cérebro é a base biológica das funções psicológicas; a noção de que tais funções fundam-se nas relações sociais, necessariamente históricas e culturais; e a interpretação de que as funções psicológicas superiores são mediadas simbolicamente (Oliveira, 1993).

Infelizmente, a morte prematura de Vygotsky subtraiu-lhe a possibilidade de desenvolver as relações entre o cérebro e o funcionamento psicológico. Um de seus principais colaboradores e continuador de sua obra, no entanto veio a se tornar conhecido como o pai da neuropsicologia: A. R. Luria (1902-1977), que deu um grande impulso ao desenvolvimento das neurociências. No que diz respeito às relações sociais, sua importância fica clara ao afirmar Vygostky que toda função psicológica surge inicialmente no nível social, interpsicológico; para depois ser internalizada, passando para o nível individual, intrapsicológico. Um dos melhores exemplos seria a linguagem. Ela surge em razão da necessidade de comunicação da criança com os demais membros de seu grupo, passando posteriormente a mediar suas representações mentais uma vez que é um sistema simbólico; e também a exercer um importante papel no autocontrole do comportamento, por exemplo, planejando ações para a resolução de problemas. Ademais, funções como percepção, atenção e memória, que em outras espécies são imediatas; isto é, diretas, não mediadas; no ser humano adquirem status de funções psicológicas superiores justamente em razão do papel mediador da linguagem. Tais funções possuem possibilidades e limites biologicamente determinados. Tomando como exemplo a percepção visual, um macaco tem um sistema ótico semelhante ao do homem. Ambos vêem cores, luzes e formas. Mas se para o macaco, em algumas situações isso é apenas um amontado de "informações" sem sentido, o homem é capaz de atribuir significado ao que vê e o faz graças à linguagem.

\section{A pesquisa com bebês}

O trabalho de Piaget e Vygotsky significou um grande impulso na atual busca pela compreensão da cognição humana, a qual tem se dado através de critérios e procedimentos cada vez mais cientificamente rigorosos. Quanto à abordagem vygotskyana da importância da mediação social no desenvolvimento cognitivo, ela é consistente com evidências experimentais de que muitas regiões neocorticais e subcorticais exibem mudanças moleculares, neuronais e estruturais em resposta a experiências como aprendizado, lesões e até terapias comportamentais (Buonomano \& Merzenich, 1998; Temple \& cols., 2003).

Piaget, por sua vez, estava aproximadamente correto ao correlacionar padrões de desempenho a faixas etárias em que ocorrem (mas para uma discussão sobre pesquisa correlacional em psicologia do desenvolvimento, veja Schlinger Jr., 1995; especialmente o Capítulo 2). Contudo ele pode ter subestimado a capacidade das crianças. Vários estudos apontam nessa direção, entre eles o de 
Gelman (1972), cujos resultados sugerem que crianças em idades correspondentes ao nível pré-operacional exibem a noção de conservação. Detalhes são descritos a seguir.

A autora conduziu um experimento cujo procedimento baseou-se em técnicas de shows de magia. Seus sujeitos foram 96 crianças (46 meninos e 50 meninas) de classe média, com idade variando de três a seis anos e meio. Seguindo uma fase inicial de familiarização dos sujeitos com a situação experimental, a segunda fase tinha a finalidade de criar no sujeito uma expectativa numérica sobre duas fileiras de ratinhos de brinquedo. Estes eram colocados em dois pratos com velcro e cobertos por latas. A pesquisadora, então levantava as latas de maneira que a criança pudesse ver os pratos com os falsos animais - um com três e outro com dois. Além da diferença numérica, as filleiras também diferiam entre si em comprimento e densidade. A experimentadora dizia que o prato com os três bichinhos era o "vencedor" e o outro, o "perdedor". A criança era instruída no sentido de que após os pratos serem novamente cobertos com as latas e movimentados, ela receberia um prêmio se encontrasse o prato vencedor (terceira fase). Se a criança retirasse a lata que cobria o prato perdedor e o identificasse corretamente, a experimentadora o cobria outra vez e, sem tocar nas latas, pedia à criança para mostrar onde estava o prato vencedor.

Os sujeitos foram subdivididos em dois grupos. Um deles foi exposto a uma situação na qual, ao mover as latas a experimentadora sub-repticiamente subtraía um elemento do prato vencedor (grupo subtração). Para o outro grupo, a alteração era operada apenas no comprimento ou na densidade da fileira (grupo deslocamento). Do total de tentativas, três eram selecionadas aleatoriamente para que a criança explicasse porque o prato descoberto era o vencedor (ou o perdedor).

Em sua grande maioria os sujeitos não cometeram erros. O restante fez erros sem qualquer significância estatística. Ademais, as crianças mostravam-se surpresas ao constatarem a alteração numérica, contrariamente à sua expectativa. A autora conclui que elas possuíam a regra de invariância de número o que, segundo ela é reforçado por quatro evidências: a) reação de surpresa no grupo subtração e não reação no grupo deslocamento, independente da idade; b) probabilidade relativa de os sujeitos notarem as alterações e serem capazes de descrevê-las; c) manifestação de comportamento de busca do elemento subtraído pelos sujeitos do grupo subtração, sem que os sujeitos do grupo deslocamento apresentassem semelhante comportamento; e d) as considerações dos sujeitos sobre a natureza da operação, as quais foram adequadas na maioria, segundo critérios estabelecidos pela autora.

Um segundo experimento foi feito para se verificar os efeitos da adição. Este foi idêntico ao primeiro, exceto por duas diferenças fundamentais: em primeiro lugar, era identificado como vencedor o prato com dois ratos; segundo, a condição subtração foi substituída pela condição adição - um elemento era adicionado ao conjunto com dois ratos. As 32 crianças de ambos os sexos apresentaram resultados muito semelhantes às do primeiro experimento.

Estudos como o que acabamos de descrever motivaram os pesquisadores a investigarem mais e mais as capacidades dos bebês. Resultados de pesquisas sugerem que diversas capacidades surgem muito mais precocemente do que se imaginava há não muito tempo. Desde o nascimento, bebês não só podem discriminar entre vozes masculinas $\mathrm{e}$ femininas, mas também a voz materna entre outras vozes femininas (para uma breve revisão de alguns desses estudos, ver Bee, 1996). Bergamasco (1997) propõe o uso de movimentos expressivos como indicadores de estados subjetivos no neonato. A análise de reações como choro e expressões faciais de agrado e desagrado em resposta a estímulos nociceptivos, olfativos e gustativos evidencia consciência (no sentido sinônimo de "awareness"). Recém nascidos também imitam expressões faciais, o que é tomado por alguns autores como indício de representações mentais.

Os resultados vão muito além e indicam um surpreendente nível de percepção mesmo em tenra idade. Recém nascidos são capazes de distinguir entre muitas figuras arquetípicas como círculos e cruzes e apresentam constância dos objetos em relação à sua forma (Slater, Morison \& Rose, 1982). Bebês de três meses e meio a quatro meses e meio já podem perceber algumas propriedades físicas de um corpo sólido, tal como sua impermeabilidade e sua oclusão em relação a outros corpos sólidos; e com sete meses e meio sobre a oclusão pela retenção (Aguiar \& Baillargeon, 2002). Bebês de apenas 12 meses mostraram habilidade em perceber a consistência dos objetos, diferenciando objetos rígidos e elásticos e transferindo essas informações para a modalidade visual (Slater \& Morison, 1985; Slater, Morison \& Rose, 1982). Crianças de zero a dois anos apresentam indicativos da noção de permanência do objeto e também de reversibilidade.

Resultados como os apontados acima têm sido encontrados graças ao desenvolvimento de novos métodos e procedimentos científicos. Um deles é o procedimento de habituação. Basicamente, este consiste da apresentação repetida de um estímulo ao bebê, medindo-se o tempo de fixação visual sobre ele. Normalmente, esse tempo decresce ao longo das apresentações, estabilizando-se nas últimas tentativas. Quando isso ocorre, diz-se que houve habituação. Numa fase seguinte, de teste, o estímulo familiar e outros estímulos novos são apresentados sucessivamente. Continua-se medindo o tempo de fixação visual. Se ele for maior em relação ao estímulo novo (desabituação), então infere-se que houve recordação do estímulo familiar e/ou discriminação entre este e o novo.

Tal procedimento foi usado em algumas das pesquisas com bebês mencionadas anteriormente. Mas muito mais impressionantes e intrigantes são os achados sobre habilidades numéricas e até aritméticas em bebês. Xu e Spelke (2000) encontraram que bebês de seis meses discriminam entre conjuntos de 
numerosidades tão grandes quanto oito e 16 objetos. Estudos anteriores sugeriram a mesma capacidade para valores menores, como dois e três (Starkey \& Cooper, 1980) inclusive em neonatos (Antell \& Keating, 1983); variando-se a natureza dos itens, seu tamanho e configuração (Strauss \& Curtis, 1981) e até mesmo com conjuntos de modalidades sensoriais cruzadas (Starkey, Spelke \& Gelman, 1983). Considerando que os sujeitos de $\mathrm{Xu}$ e Spelke (2000) não discriminaram entre conjuntos de oito e 12 elementos e que variáveis outras que não a numérica foram rigorosamente controladas no experimento, as autoras concluem que bebês discriminam "grandes" numerosidades dependendo da razão entre elas; e ainda, que tal capacidade se desenvolve anteriormente à aquisição da linguagem e da contagem simbólica.

Poucos anos antes da publicação do estudo de Xu e Spelke (2000), Wynn (1992) conduziu um experimento cujos resultados são ainda mais surpreendentes e polêmicos. Usando uma variação do procedimento de habituação, a autora elaborou um procedimento para verificar se bebês de cinco meses são capazes de somar e subtrair. Inicialmente foi determinada uma linha de base do tempo do olhar para conjuntos unitários e de dois bonecos. O procedimento era tal que permitia que se juntasse um boneco a outro de modo que o resultado dessa soma podia ser correto ou não, dependendo isto de manipulação conveniente do aparato empregado, cuja construção oferecia tal possibilidade. Por semelhante modo, era possível subtrair um boneco de um par, resultando em um ou dois bonecos ao final da operação. Os resultados demonstraram que, de modo consistente, todos os sujeitos da pesquisa exibiram reação de surpresa a resultados impossíveis, olhando mais tempo para área de exposição dos bonecos quando a quantidade resultante da soma ou da subtração era incorreta. A conclusão foi que além de os bebês possuírem o conceito de número, eles são dotados de habilidades aritméticas inatas. (Para uma revisão crítica de estudos sobre habilidades numéricas em bebês, ver Mix, Huttenlocher \& Levine, 2002).

\section{Inteligências múltiplas}

No entendimento de Gardner (1983), Piaget fez uma das mais completas e belas descrições do desenvolvimento das capacidades espaciais e lógicomatemáticas, porém não de todas as capacidades cognitivas do ser humano. Relacionando evidências de diversas ciências, esse autor elaborou um modelo, mais completo do que os anteriores, das nossas capacidades cognitivas e da idéia de inteligência. Notando que determinadas tarefas cognitivas são isoláveis e relativamente independentes tanto nos seus aspectos puramente cognitivos quanto nas áreas cerebrais que as processam, ele classificou várias capacidades cognitivas universalmente distribuídas pelas culturas humanas. Foram descritos sete domínios cognitivos relativamente independentes, com origens evolucionárias e trajetórias de desenvolvimento distintas, bem como áreas cerebrais relativamente especializadas para o seu processamento: inteligências lingüística, lógico- matemática, musical, espacial, cinestésico-corporal, intrapessoal e interpessoal.

Evidências advindas de estudos antropológicos, psicológicos e neurocientíficos têm provido sólidos fundamentos científicos sobre o desenvolvimento de diversas de nossas capacidades cognitivas e sua origem evolutiva (Andrade \& Bhattacharya, 2003; Chugani, 1998; Culham \& Kanwisher, 2001; Kuhl, Tsao, Liu, Zhang \& Boer, 2001; Dehaene, Spelke, Pinel, Stanescu \& Tsivkin, 1999; Dehaene, Piazza, Pinel \& Cohen, no prelo; e para duas interpretações alternativas, ver: Donahoe \& Palmer, 1994 e Schlinger Jr., 1995). Atualmente, as capacidades cognitivas têm sido divididas em sistemas cognitivos: sociais, biológicos e físicos. A seguir, apresentamos uma breve descrição de cada um deles.

\section{Sistemas Cognitivos Sociais}

Estudos com lesões e neuroimagens mostram que uma significativa porção do cérebro humano é devotada ao comportamento social e que, nos humanos, as áreas neocorticais são maiores e apresentam microcircuitos mais complexos do que nos outros primatas. $\mathrm{O}$ córtex pré-frontal, principal centro do planejamento e controle das emoções, é a parte evolutivamente mais recente do neocórtex e se comunica com importantes regiões perceptivas através de seus neurônios altamente multimodais, ocupando uma porção muito maior no cérebro humano do que nos outros animais (Geary, 2001; Miller, Freedman \& Wallis, 2002). E em conjunto com regiões específicas do córtex temporal e junções têmporo-parietais, também participa no processamento da linguagem verbal e da música. Portanto, sistemas neuronais mais ou menos distintos e específicos foram desenvolvidos para atender e processar competências sociocognitivas tais como a linguagem, inferências sobre os sentimentos próprios e de outros indivíduos, habilidades de processamento facial e comunicação não verbal como a música que, estreitamente relacionada à linguagem, parece servir a aspectos socioemocionais importantes, como a união do grupo e reprodução (Andrade \& Bhattacharya, 2003; Besson \& Schon, 2001; Huron, 2001).

\section{Sistemas cognitivos biológicos}

Estudos etnobiológicos mostram que sistemas préindustriais de categorização são universalmente distribuídos e muito similares às classificações científicas. Os estudos a respeito das áreas corticais relativamente especializadas nesse sentido ainda são pouco consistentes, mas ainda assim sugerem diferentes sistemas neuronais na categorização de seres vivos e inanimados. Danos na porção posterior do neocórtex impossibilitam ao paciente nomear coisas vivas, mas deixam intacta a capacidade de nomear objetos inanimados ou vice-versa, mostrando uma dupla dissociação desses sistemas.

\section{Sistemas Cognitivos Físicos}

O processamento cognitivo do espaço físico e suas representações mentais engajam áreas específicas do córtex parietal superior além da participação de algumas regiões dos lobos temporais na memória espacial, principalmente o hipocampo (Burgess \& 
cols., 1999; Culham \& Kanwisher, 2001). A capacidade de julgar quantidades relativas de itens no campo visual permite que animais sociais façam julgamentos sobre a quantidade de amigos ou inimigos, sobre a disponibilidade de alimentos e outros itens, o que a torna altamente adaptativa (Nieder, Freedman \& Miller, 2002) e também indica a natureza visuoespacial do processamento numérico, que tem nas áreas do lobo parietal superior seus principais substratos neuronais (Dehaene \& cols., no prelo).

Em suma, a neurociência cognitiva dá o respaldo fundamental às evidências culturais e comportamentais. Testes psicológicos cada vez mais criteriosos permitem determinar quais tipos de déficits cognitivos afligem os pacientes com lesões cerebrais, indicando-nos as regiões cerebrais relativamente especializadas para as funções cognitivas. Ademais, os estudos com imagens cerebrais nos permitem observar quais as regiões envolvidas no processamento das capacidades cognitivas testadas e, além de confirmar a participação daquelas regiões essenciais observadas nos estudos com lesões, observar também o envolvimento de outras regiões não envolvidas nas lesões. Nesse processo podemos saber como as tarefas cognitivas envolvem as diversas regiões cerebrais e como elas se relacionam. Por exemplo, hoje há evidências de que os processos mentais visuo-espaciais são fundamentais no raciocínio matemático e que determinadas áreas intraparietais são especializadas no processamento numérico (Dehaene \& cols., no prelo). Também sabemos que muito do aprendizado da linguagem e da música possuem uma trajetória de desenvolvimento entrelaçada e que as manifestações musicais parecem anteceder as lingüísticas, inclusive dando suporte a estas, e ambas se dão através do processamento auditivo desde o nascimento e até mesmo antes dele. A sintaxe lingüística parece ser processada nas mesmas regiões cerebrais da sintaxe musical e ambas produzem eventos neuroelétricos similares (Maess, Koelsch, Gunter \& Friederici, 2001; Koelsch \& cols., 2002).

Esses novos conhecimentos sobre a relativa independência de determinadas capacidades cognitivas, bem como sua interação na realização de tarefas acadêmicas e do mundo real, geram importantes implicações para a educação. Consideremos algumas delas.

\section{Implicações educacionais}

Uma importante implicação educacional é que o desenvolvimento histórico das disciplinas científicas e acadêmicas está baseado em sistemas cognitivos evolutivamente determinados o que, em última instância, indica que se deve estudar, cada vez mais, como os sistemas cognitivos básicos se relacionam com cada uma das competências acadêmicas no sentido de se determinar abordagens instrucionais mais eficientes, que estimulem e utilizem os sistemas cognitivos relacionados, desenvolvendo mais eficazmente os conceitos acadêmicos. Isto possibilitará o desenvolvimenmto de conceitos acadêmicos e abordagens instrucionais mais eficientes que estimulem e explorem adequadamente os sistemas cognitivos relacionados às atividades dentro e fora da sala de aula.

Geary (1996, 2001), baseando-se em pesquisas sobre habilidades numéricas com bebês, com animais e interculturais, afirma que a presença de algumas dessas habilidades são produto de pressões evolutivas e, denominando-as "habilidades biologicamente primárias", conclui que estas constituem o esqueleto sobre o qual se desenvolverão outras mais complexas, as quais denomina "habilidades biologicamente secundárias" - como a aprendizagem dos símbolos numéricos e algébricos, do uso do sistema decimal, dos cálculos etc. Estas dependem das primárias, mas seu desenvolvimento se deve também à valoração cultural e a práticas escolares, as quais diferem de um país para outro. Resultados de pesquisas interculturais apontam diferenças significativas, desfavoráveis para estudantes americanos em relação a estudantes de países asiáticos, o que leva o autor a constatar:

\begin{abstract}
Eu tenho notado que o construtivismo é amplamente um reflexo das atuais crenças culturais americanas e, como tal, envolve o desenvolvimento de técnicas instrucionais que tentam fazer da aquisição de habilidades matemáticas complexas uma empreitada social prazerosa que será perseguida baseada no interesse e na escolha individuais (Geary, 1996, p. 166).
\end{abstract}

Mas se o meio cultural valoriza mais a prática esportiva, por exemplo, como diz o autor ser o que ocorre em seu país, a maior parte das crianças se dedicará ao esporte, deixando a matemática em plano inferior. Portanto, sem contar com uma maior valorização cultural de habilidades matemáticas, a escola deveria investir mais no seu ensino direto.

D. C. Geary tem um interesse especial pela matemática e sua posição com relação ao ensino dessa disciplina procede, pois ensinar é a função da precípua da escola. Mas os resultados das pesquisas nos permitem ir além. Outra implicação relaciona-se ao fenômeno, há muito observado, da transferência de aprendizagem de um domínio para o outro, a qual se dá, em maior ou menor grau, na medida em que as tarefas compartilham elementos neurológicos comuns. Hoje, evidências a partir de testes psicológicos e seus correlatos neuronais além de sugerirem a existência de domínios cognitivos relativamente independentes, mostram como as transferências entre domínios podem ocorrer. Por exemplo, há estudos que sugerem fortemente um grande envolvimento de processos espaço-temporais e até mesmo visuo-espaciais no processamento musical. Isso nos permite pensar na possibilidade de transferências de aprendizagem entre música e matemática. Se ambas são processadas em áreas do cérebro envolvidas também no processamento visuo-espacial, parece bastante provável que o ensino de uma redundaria em benefício para o aprendizado da outra.

A compreensão do funcionamento do cérebro nos fornece fundamentos sólidos para a reformulação de 
metodologias de ensino. Contudo, as possibilidades abertas pelo conhecimento atual não devem nos conduzir a um retorno a práticas pedagógicas verbalistas. Estas, apesar de todo discurso contrário, continuam sendo amplamente adotadas. $\mathrm{O}$ benefício na aprendizagem matemática através do ensino da música e vice-versa, tomando essas disciplinas apenas à guisa de exemplo, só seria possível se se buscassem alternativas pedagógicas que valorizassem a espacialidade e a temporalidade de ambas em lugar de se ensinar o uso mecânico de regras, símbolos, algoritmos, técnicas etc. Eis um campo aberto de pesquisa para pedagogos, psicólogos da educação e da aprendizagem etc.

Os novos avanços nos permitem enxergar, por exemplo, que nossas crenças culturais se refletem na negligência de domínios cognitivos evolutivamente determinados e com papéis fundamentais na formação do indivíduo e da sociedade como tais, como o caso da música e das relações sociais. A abordagem desses domínios pela sua mera e descuidada inserção em temas transversais nos currículos escolares está longe de ser adequada e, muito menos, suficiente.

Um ponto ulterior que merece nossa atenção nessa discussão sobre implicações educacionais da pesquisa psicológica e neurocientífica diz respeito às faixas etárias em que ocorrem os estágios de desenvolvimento. Interpretações equivocadas podem levar-nos, e infelizmente nos têm levado muitas vezes, a um determinismo do tipo: "Não adianta insistir com esse aluno porque ele ainda não alcançou o estágio que permite aprender isso" (seja "isso" o que for). Aqui podemos recorrer a uma importante posição de Vygotsky, para quem o aprendizado impulsiona o desenvolvimento: "O único bom ensino é aquele que se adianta ao desenvolvimento" (Oliveira, 1993, p. 62). Como temos visto, a natureza parece ter sido bem mais gentil conosco do que supúnhamos há algum tempo. Ela nos dotou com habilidades que se apresentam muito mais precocemente do que os métodos de Piaget, apesar de sua genialidade e inventividade, lhe permitiram detectar. Podemos pensar na possibilidade de ensinarmos coisas cada vez mais complexas em idades progressivamente inferiores.

E se devemos relativizar a questão dos estágios, devemos também abandonar, ou pelo menos relativizar, nossas concepções sobre talento. Estas, em geral, são baseadas no senso comum e carentes de suporte científico. Howe, Davidson e Sloboda (1998) apontam sérios problemas na pesquisa sobre talentos e concluem:

As evidências que nós levantamos neste artigo não fornecem apoio à abordagem do talento, segundo a qual a excelência é uma conseqüência da posse de dons inatos. Essa conclusão tem implicações práticas, pois a categorização de algumas crianças como inatamente talentosas é discriminatória. As evidências sugerem que tal categorização é injusta e imprevidente, impedindo jovens de perseguir um alvo por causa da convicção injustificada de pais e professores de que eles não se beneficiariam de oportunidades superiores dadas àqueles julgados talentosos (p. 430).

Portanto, não temos que esperar por alunos talentosos. Antes, nossas expectativas com relação aos nossos alunos devem ser sempre as mais elevadas, já que nossa crença na sua capacidade não é gratuita, mas fundamenta-se em evidências científicas. A estas temos de fazer corresponder avanços nos métodos de ensino.

O conhecimento do cérebro aponta na direção sugerida acima. A uma certa idade as conexões entre os neurônios chegam ao seu número máximo, o que torna qualquer aprendizagem muito mais fácil, rápida e duradoura. As conexões não utilizadas, por uma questão de economia do organismo, vão se desfazendo com o passar do tempo. E o que se chama "poda". Claro que a capacidade para aprender permanece. Mas as aprendizagens serão mais lentas e dificultosas, exigindo muito mais investimento de tempo e energia no ensino.

Ensinar coisas mais complexas a crianças mais jovens, embora teoricamente possível, impõe riscos sobre os quais deve haver reflexão e debate exaustivos. E, sobretudo, muita pesquisa. Um cuidado importante é o de não elevar os níveis de estresse da criança. Queremos que as crianças aprendam o máximo do que podemos ensinar a elas. Mas também as queremos saudáveis e felizes. Portanto, os métodos de ensino são um importante alvo de pesquisa séria, criteriosa, constante e informada pelos avanços científicos da psicologia e da neurociência cognitivas. Por um outro lado, entretanto, isso pode ter reflexos positivos importantes no âmbito social mais amplo. $\mathrm{O}$ aprendizado mais precoce poderá melhorar significativamente o aproveitamento escolar em séries e níveis educacionais mais avançados. Isso significa profissionais, cientistas, pessoas, enfim, melhor preparados para o exercício profissional, para a geração de conhecimento, para a elevação dos níveis de qualidade de vida e a construção de uma sociedade mais justa.

Há, portanto, uma inequívoca necessidade de atualização curricular das universidades e dos profissionais da educação em relação aos avanços científicos, de modo que isso se reflita também nos níveis inferiores de educação escolar. Nesse sentido, gostaríamos de finalizar comentando uma pesquisa recentemente realizada por Omote, Prado e Carrara (2003).

Compuseram a amostra estudantes de pósgraduação em educação (mestrado e doutorado), mais da metade dos quais com formação em pedagogia e psicologia. Os participantes responderam um questionário eletrônico - versão utilizada para evitar erros de preenchimento e inserir automaticamente as respostas em um banco de dados, facilitando posterior análise - contendo itens que visavam a caracterização 
de seus hábitos de pesquisa bibliográfica. Consideramos importante destacar que:

Os resultados indicam que as fontes principais de informação utilizadas por esses estudantes, na realização de sua pesquisa bibliográfica, referem-se a livros e periódicos, apontados por 59 e 53 participantes, respectivamente, sendo indicados como duas fontes mais importantes (postos médios 1,73 e 2,19)... As bases eletrônicas de dados, amplamente disponíveis na biblioteca universitária, são também utilizadas com freqüência, com a indicação por 44 estudantes, mas não são tão valorizadas quanto os livros e periódicos (posto médio 3,14). (Omote, Prado \& Carrara, 2003).

Pois, como discutem os autores:

Esses resultados sugerem um amplo uso que os alunos de pós-graduação fazem de diferentes recursos na realização de sua pesquisa bibliográfica. Entretanto, alguns detalhes merecem destaque. Na amostra de estudantes de pós-graduação, parece haver uma subutilização das possibilidades oferecidas pelas bases de dados eletrônicas. As bases de dados eletrônicas, que representam hoje uma fonte de extrema relevância, pela abrangência, atualidade, e facilidade e rapidez de acesso, embora sejam utilizadas por pouco mais de 2/3 da amostra, não são consideradas especialmente importantes. Só não perdem, na ordem de importância, para documentos diversos (Omote, Prado \& Carrara, 2003).

Em áreas como a psicologia e, principalmente na das neurociências, os livros costumam tratar de um conhecimento fundamental e, portanto, mais sistematizado e consolidado. Eles representam, pois, uma fonte de informações com utilidade de longo prazo. Contudo, a efervescência do conhecimento em processo de produção, as pesquisas mais recentes e o debate mais atual encontram-se nos periódicos científicos. Ora, não só avança o conhecimento, como avançam as tecnologias de informação. Por conseguinte, é indispensável que se saiba fazer bom uso destas para ter acesso ao conhecimento e manterse atualizado. É imprescindível que, além de dispor dos recursos mais modernos e variados de acesso à informação científica, a universidade também ensine e estimule seu uso.

\section{REFERÊNCIAS}

Aguiar, A. \& Baillargeon R. (2002). Developments in young infants' reasoning about occluded objects. Cognitive Psychology, 45 (2), 267-336.

Andrade, P. E. \& Bhattacharya, J. (2003). Brain tuned to music. Journal of Royal Society for Medicine, 96, 284-287.

Antell, S. \& Keating, D. P. (1983). Perception of numerical invariance in neonates. Child Development, 54, 695-701.
Bee, H. (1996). A criança em desenvolvimento (7 ${ }^{\mathrm{a}}$ ed.). (M. A. V. Veronese, Trad.). Porto Alegre: Artes Médicas.

Bergamasco, N. H. P. (1997). Expressão facial como acesso à consciência do recém-nascido. Psicologia USP, 8 (2), 275286.

Besson, M. \& Schon, D. (2001). Comparison between language and music. Annals of the New York Academy of Sciences, 930, $232-58$.

Buonomano, D. V. \& Merzenich, M. M. (1998). Cortical plasticity: From synapses to maps. Annual Review of Neuroscience, 21, 149-186

Burgess, N.; Maguire, E. A.; Spiers, H. J.; O'Keefe, J.; Epstein, R.; Harris, A.; Stanley, D. \& Kanwisher, N. (1999). The parahippocampal place area: Recognition, navigation, or encoding? Neuron, 23, 115-125.

Chugani, H. T. (1998). Biological basis of emotions: Brain systems and brain development. Pediatrics, 102 (5), 12251229.

Culham, J. C. \& Kanwisher, N. G. (2001). Neuroimaging of cognitive functions in human parietal cortex. Current Opinion in Neurobiology, 11, 157-163.

Dehaene, S.; Piazza, M.; Pinel, P. \& Cohen, L. (no prelo). Three parietal circuits for number processing. Neuropsychology.

Dehaene, S.; Spelke, E.; Pinel, P.; Stanescu, R. \& Tsivkin, S. (1999). Sources of mathematical thinking: Behavioral and brain imaging evidence. Science, 284, 970-974.

Donahoe, J. W. \& Palmer, D. C. (1994). Learning and complex behavior. Boston: Allyn and Bacon.

Gardner, H. (1983). Frames of mind: The theory of multiple intelligences. Basic Books: New York.

Geary, D. C. (1996). Biology, culture, and cross-national differences in mathematical ability. Em R. J. Sternberg \& T. Ben-Zeev (Orgs.), The nature of mathematical thinking (pp. 145-171). Mahwah, NJ: Lawrence Earlbaum Associates.

Geary, D. C. (2001). A darwinian perspective on mathematics and instruction. Em T. Loveless (Org.), The great curriculum debate: How should we teach reading and math? (pp. 85-107). Washington, DC: Brookings Institute.

Gelman, R. (1972). Logical capacity of very young children: Number invariance rules. Child Development, 43, 75-90.

Howe, M. J. A.; Davidson, J. W. \& Sloboda, J. A. (1998). Innate talents: Reality or myth? Behavioral and Brain Sciences, 21, 399-442.

Huron, D. (2001). Is music an evolutionary adaptation? Em R. Zatorre \& I. Peretz (Orgs.), The Biological Foundations of Music (pp. 43-61). New York: Academy of Sciences.

Koelsch, S.; Gunter, T. C.; Cramon, D. Y.; Zysset, S.; Lohmann, G. \& Friederici, A. D. (2002). Bach Speaks: A Cortical "Language-Network" Serves the Processing of Music, Neuroimage, 17(2), 956-966.

Kuhl, P. K.; Tsao, F.; Liu, H.; Zhang, Y. \& Boer, B. (2001). Language/Culture/Mind/Brain: Progress at the margins between disciplines. Annals of the New York Academy of Sciences, 935, 136-174.

Maess, B.; Koelsch, S.; Gunter, T. C. \& Friederici, A. D. (2001). Musical suntax is processed in Broca's area: An MEG study. Nature Neuroscience, 4, 540-545.

Miller, E. K; Freedman, D. J. \& Wallis, J. D. (2002). The prefrontal cortex: Categories, concepts and cognition. Philosophical Transactions: Biological Sciences, 357, 11231136.

Mix, K. S.; Huttenlocher, J. \& Levine, S. C. (2002). Multiple cues for quantification in infancy: Is number one of them? Psychological Bulletin, 128 (2), 278-294.

Nieder, A.; Freedman, D. J. \& Miller, E. K. (2002). Representation of the quantity of visual items in the primate prefrontal cortex. Science, 297, 1708-1711.

Oliveira, M. K. (1993). Vygotsky: Aprendizado e desenvolvimento: Um processo sócio-histórico. São Paulo: Scipione.

Omote, S.; Prado, P. S. T. \& Carrara, K. (2003). O uso de fontes de referência na pesquisa bibliográfica por alunos de pós- 
graduação em educação. Anais do V Simpósio em Filosofia e Ciência. Marília, SP: Unesp Marília Publicações. CD-ROM.

Piaget, J. \& Szeminska, A. (1941/1981). A gênese do número na criança ( $3^{\mathrm{a}}$ ed.). (C. M. Oiticica, Trad.). Rio de Janeiro: Zahar Editores.

Schlinger Jr., H. D. (1995). A behavior analytic view of child development. Plenum Press: New York.

Slater, A. \& Morison, V. (1985). Shape constancy and slant perception at birth. Perception, 14 (3), 337-344.

Slater, A.; Morison, V. \& Rose, D. (1982). Visual memory at birth. British Journal of Psychology, 73, 519- 525.

Starkey, P. \& Cooper, R. G. (1980). Perception of numbers by human infants. Science, 210, 1033-1035.

Starkey, P., Spelke, E. S. \& Gelman, R. (1983). Detection of intermodal numerical correspondences by human infants. Science, 222, 179-181.

Strauss, M. S. \& Curtis, L. E. (1981). Infant perception of numerosity. Child Development, 52, 1146-1152.

Temple, E.; Deutsch, G. K.; Poldrack, R. A.; Miller, S. L.; Tallal, P.; Merzenich, M. \& Gabrieli, J. D. E. (2003). Neural deficits in children with dyslexia ameliorated by behavioral remediation: Evidence from functional MRI. Proceedings of National Academy of Science, 100 (5), 2860-2865.

Xu, F. \& Spelke, E. S. (2000). Large number discrimination in 6month-old infants. Cognition, 74, B1-B11.

Wynn, K. (1992). Addition and subtraction by human infants. Nature, 358, 749-750.

Recebido: 20.09.2003

Revisado: 22.10.2003

Aceito: 10.11.2003 


\section{Sobre os autores:}

Paulo Estevão Andrade: músico profissional e atua como professor na área de musicalização infantil no Colégio Criativo, em Marília (SP). Autodidata estudioso das neurociências e psicologia cognitivas, o autor desenvolveu uma pedagogia musical baseada no conhecimento produzido por essas ciências. Recentemente, publicou um artigo no Journal of Royal Society for Medicine em co-autoria com Joydeep Bhattacharya, do California Institute of Technology (USA). Atualmente trabalha na conclusão de uma pesquisa no campo da percepção musical, em que avalia a capacidade, em crianças de primeira a quarta séries, de relacionar os modos maior e menor da música tonal a estados emocionais.

Paulo Sérgio T. do Prado: mestre em Educação pela UFSCar e doutor em Psicologia Experimental pela USP. Docente do curso de pedagogia da Faculdade de Filosofia e Ciências da UNESP (campus de Marília, SP), ministra disciplinas relacionadas à psicologia da educação e da aprendizagem. Ocupando atualmente o cargo de vice-chefe do Departamento de Psicologia da Educação, tem desenvolvido pesquisas sobre habilidades numéricas e perceptuais, tendo contribuído recentemente numa pesquisa sobre formação de pesquisadores em educação. Endereço para correspondência: FFC-UNESP - Marília - Departamento de Psicologia da Educação Av. Hygino Muzzi Filho, 737 - Campus Universitário - 17525-900 - Marília, SP E-mail: pradopst@ marilia.unesp.br. 